\title{
Guest Recognition with Micelle-Bound Cavitands
}

\section{Supporting Information}

Michael P. Schramm, Richard J. Hooley, and Julius Rebek, Jr.*

The Skaggs Institute for Chemical Biology and the Department of Chemistry, The Scripps Research Institute MB-26, 10550 North Torrey Pines Rd., La Jolla, CA 92037.

jrebek@scripps.edu

\section{Synthesis of New Compounds}

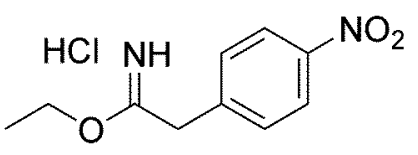

\section{Synthesis of Ethyl 2-(4-nitrophenyl)acetimidate hydrochloride, S1:}

To an oven-dried, $100 \mathrm{~mL}$ round-bottomed flask equipped with a magnetic stirrer was added (4-nitrophenyl)acetonitrile (2.96 g, $18.3 \mathrm{mmol})$, anhydrous ethanol (31 mmol, 1.7 $\mathrm{mL})$ and anhydrous toluene $(30 \mathrm{~mL})$. The mixture was cooled to $-10{ }^{\circ} \mathrm{C}$ and hydrogen chloride gas was bubbled into the solution for $20 \mathrm{~min}$. The flask was sealed, and stirred at $23{ }^{\circ} \mathrm{C}$ for $16 \mathrm{~h}$. The solvent was removed in vacuo, anhydrous ether $(200 \mathrm{~mL})$ was added and the resulting white solid removed by vacuum filtration. The solid was quickly washed with anhydrous ether $(2 \times 50 \mathrm{~mL})$ and dried under vacuum to yield (4nitrophenyl)acetimidate hydrochloride (3.15 g, 71\%) which was used without further purification. ${ }^{1} \mathrm{H}$ NMR $\left(600 \mathrm{MHz}, \mathrm{DMSO}-d_{6}\right) \delta 1.27(\mathrm{t}, \mathrm{J}=6.6 \mathrm{~Hz}, 3 \mathrm{H}) ; 1.28(\mathrm{~m}, 4 \mathrm{H})$; $4.24(\mathrm{~s}, 2 \mathrm{H}) ; 4.43$ (q, J = 6.6 Hz, 2H); $7.68(\mathrm{~d}, \mathrm{~J}=8.4 \mathrm{~Hz}, 2 \mathrm{H}) ; 8.24(\mathrm{~d}, \mathrm{~J}=8.4 \mathrm{~Hz}, 2 \mathrm{H})$; 12.00 (br s, $2 \mathrm{H}) ;{ }^{13} \mathrm{C}$ NMR (150 MHz, DMSO- $\left.d_{6}\right) \delta 13.23 ; 37.86 ; 69.42 ; 123.77 ; 130.79$; 139.98; 147.10; 175.94, ESIHRMS m/z: calcd for $\mathrm{C}_{10} \mathrm{H}_{13} \mathrm{~N}_{2} \mathrm{O}_{3}\left(\mathrm{M}^{\left.-\mathrm{Cl}^{-}\right)} 209.0921\right.$; found 209.0918 . 


\section{Spectra of New Compounds}

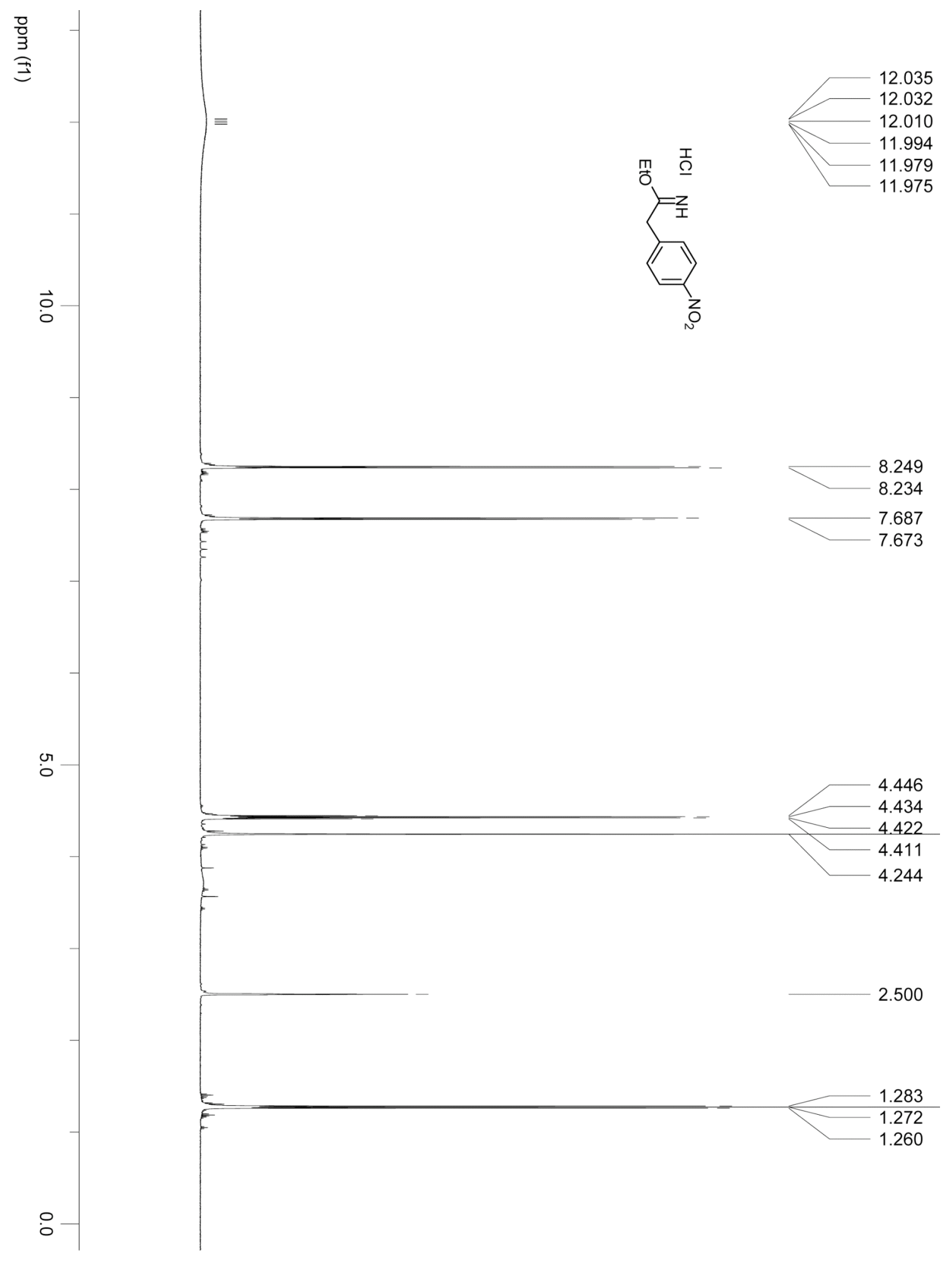




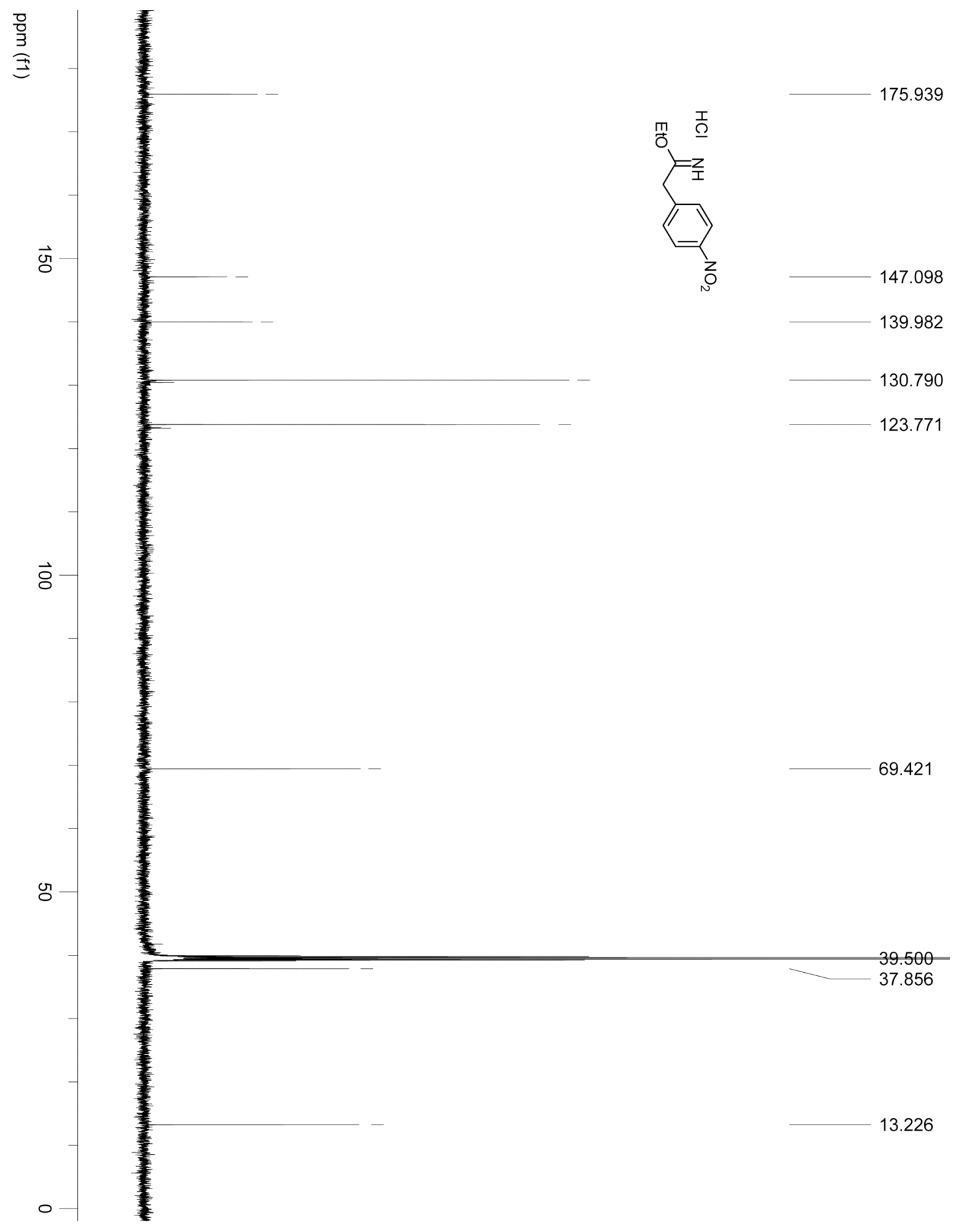




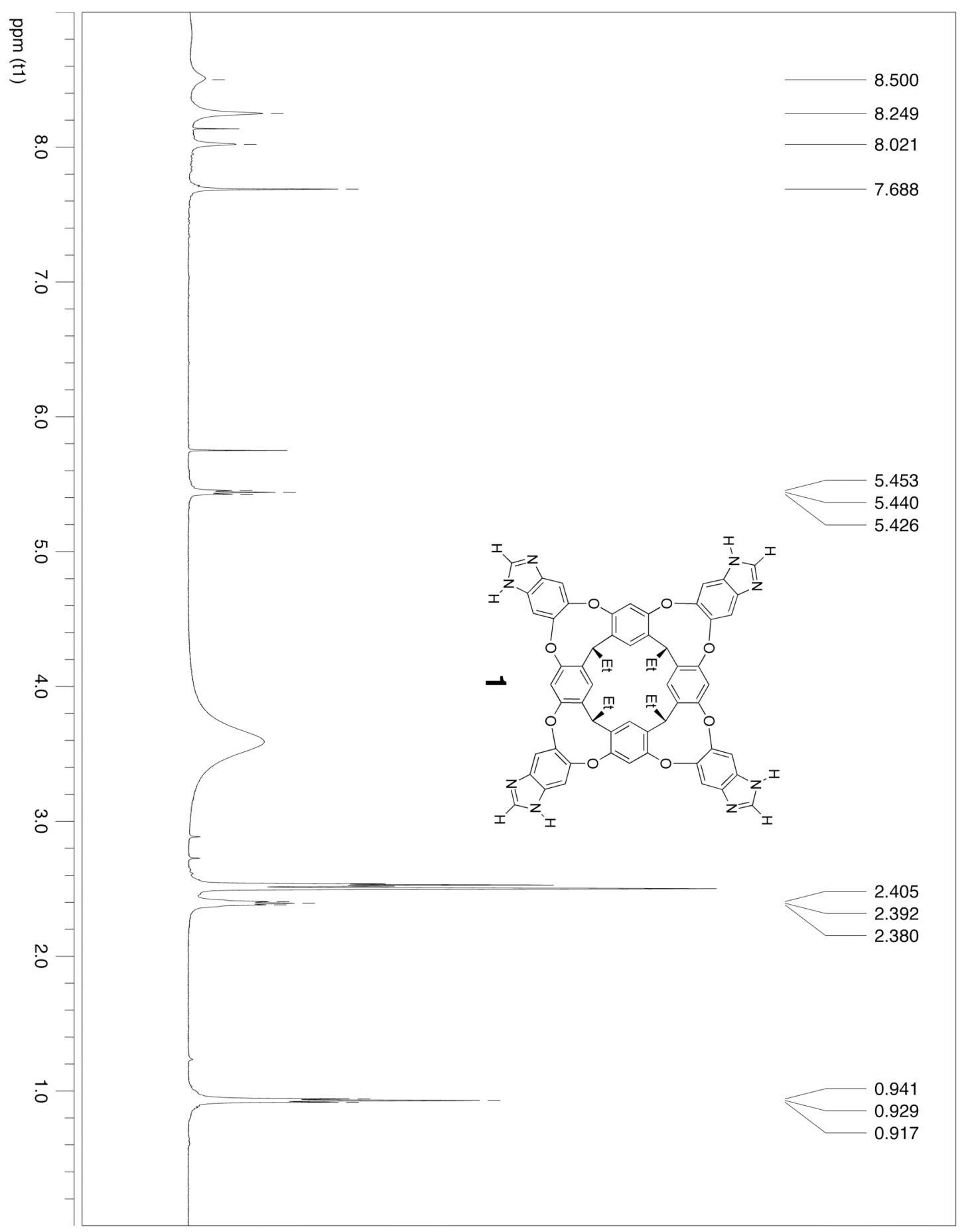




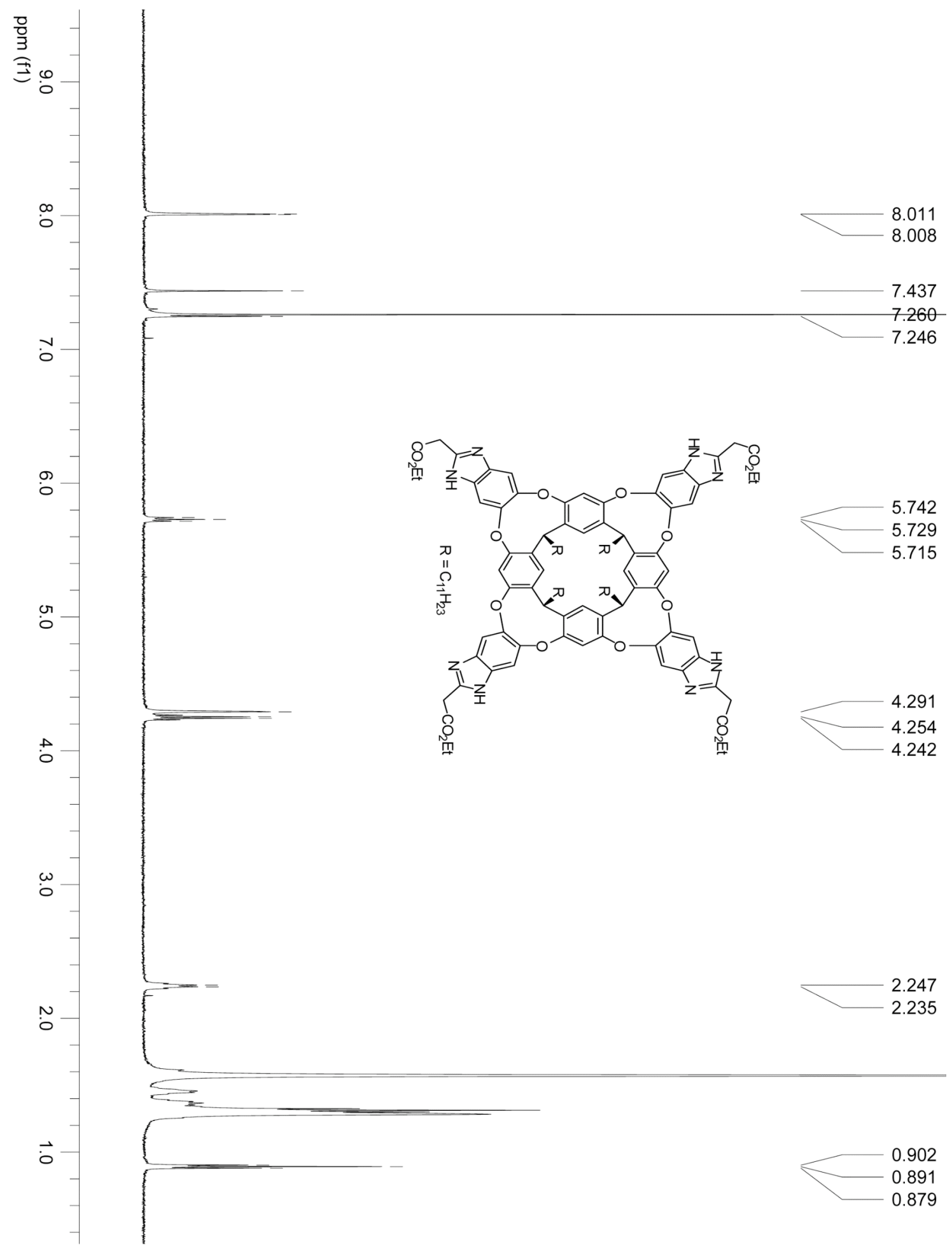




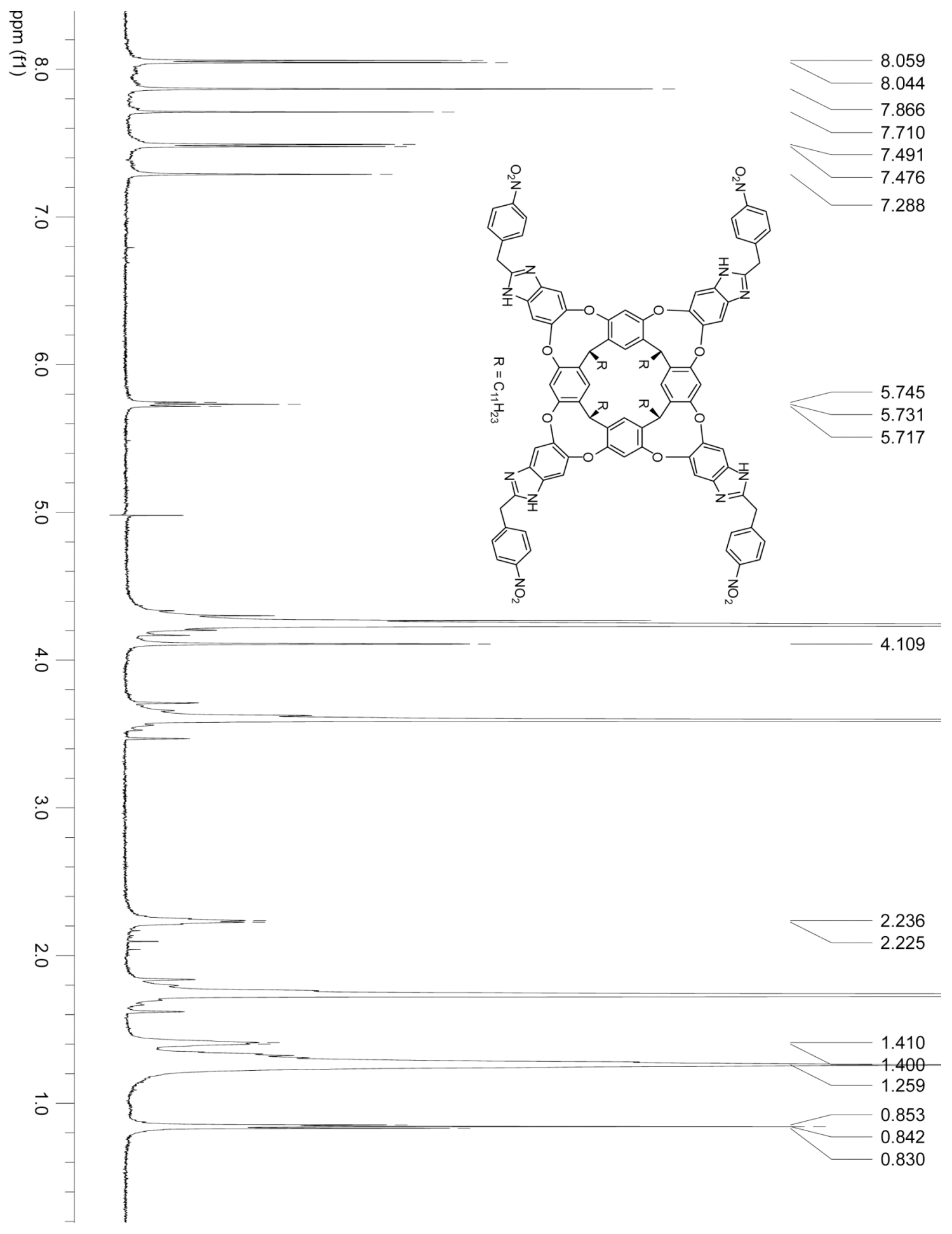




\section{Spectra of Encapsulated Guests in 1 in PC Micelles}

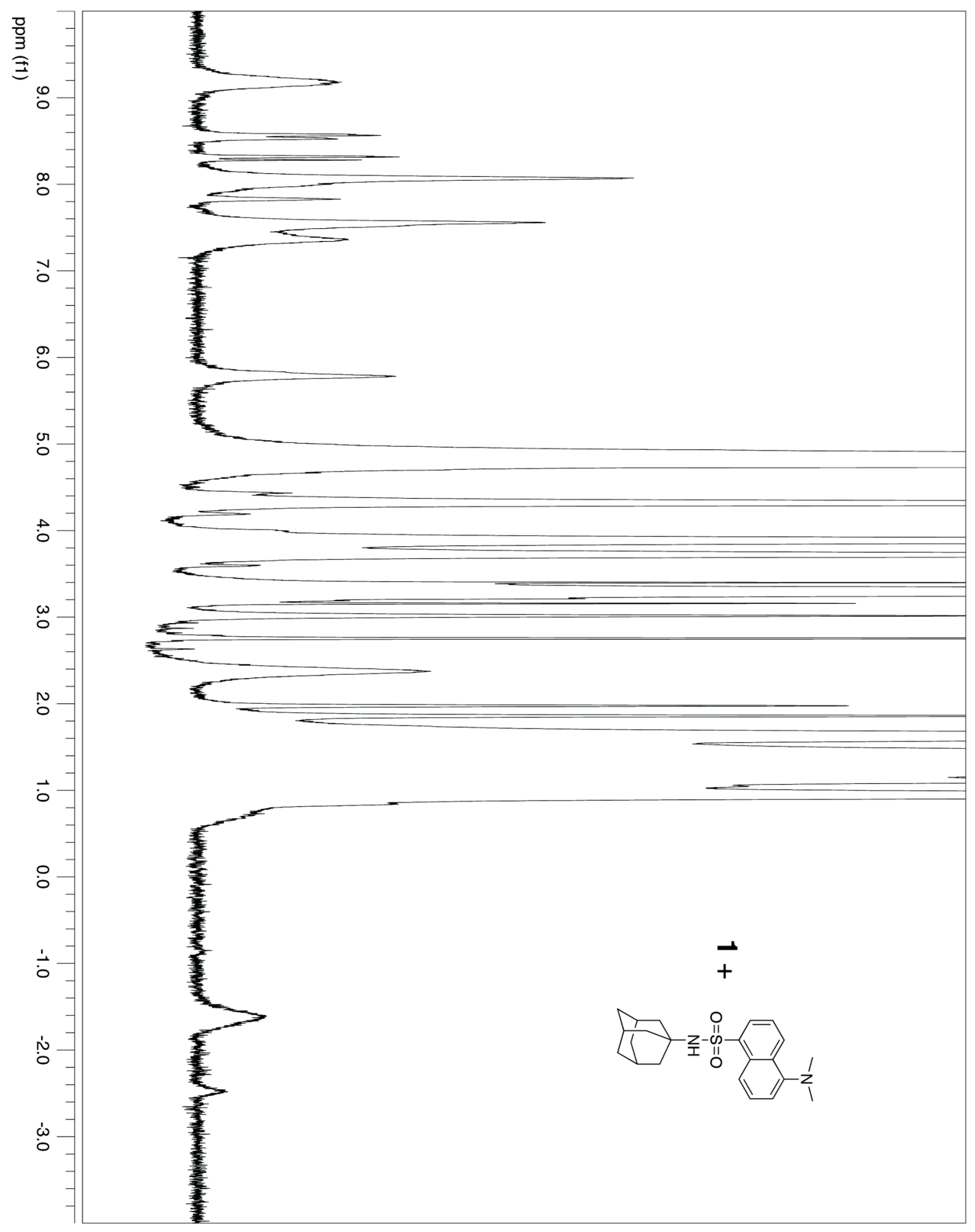




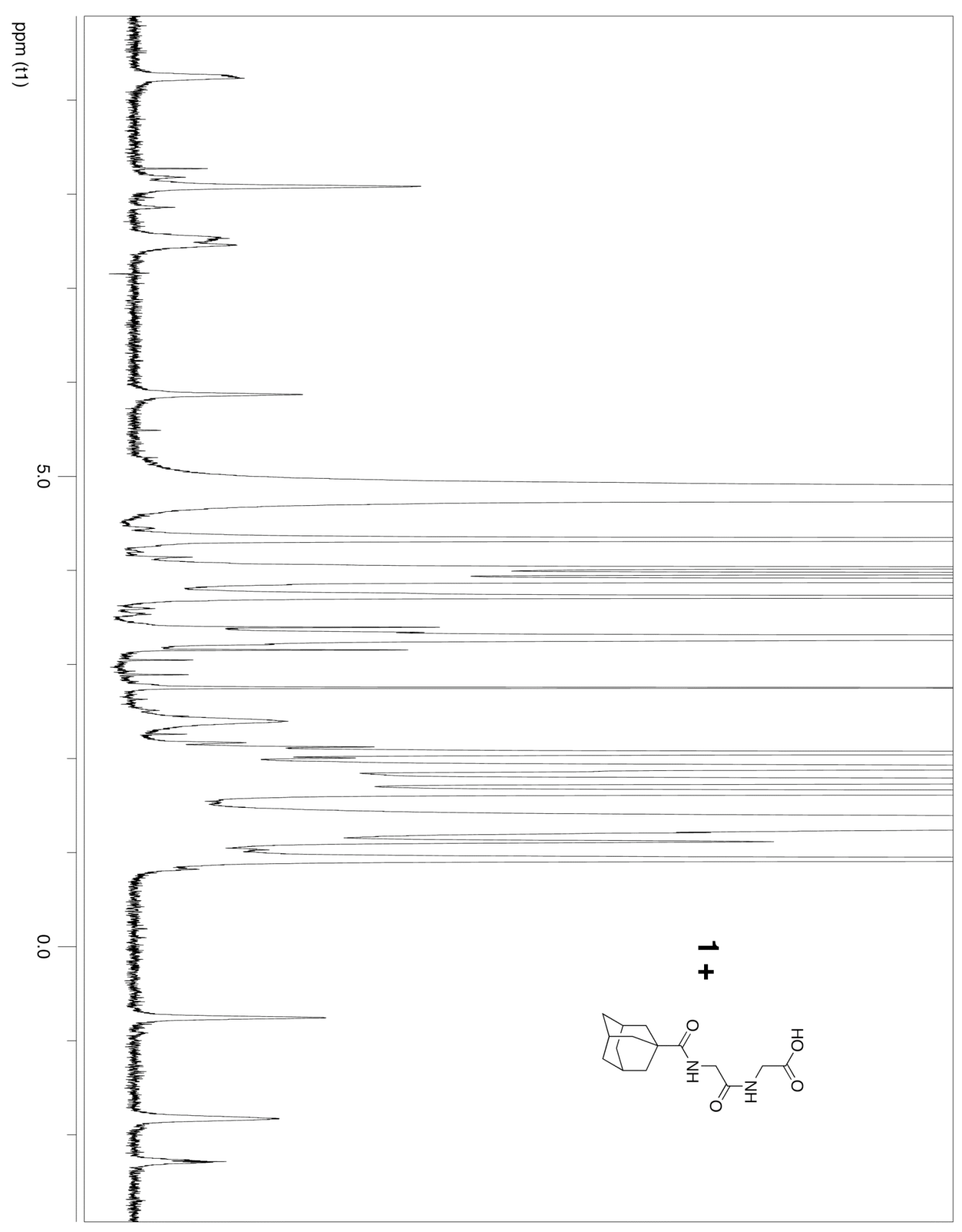




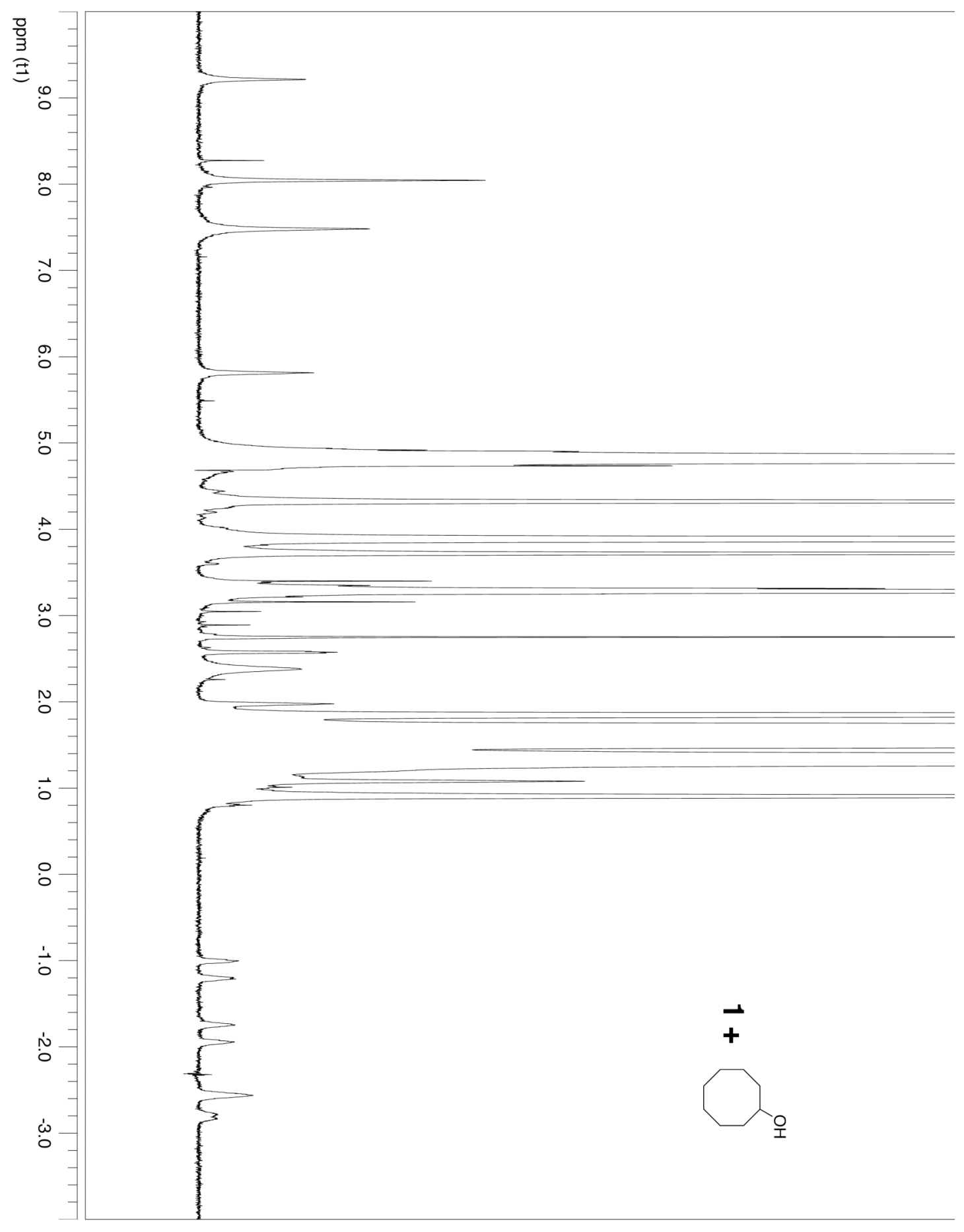




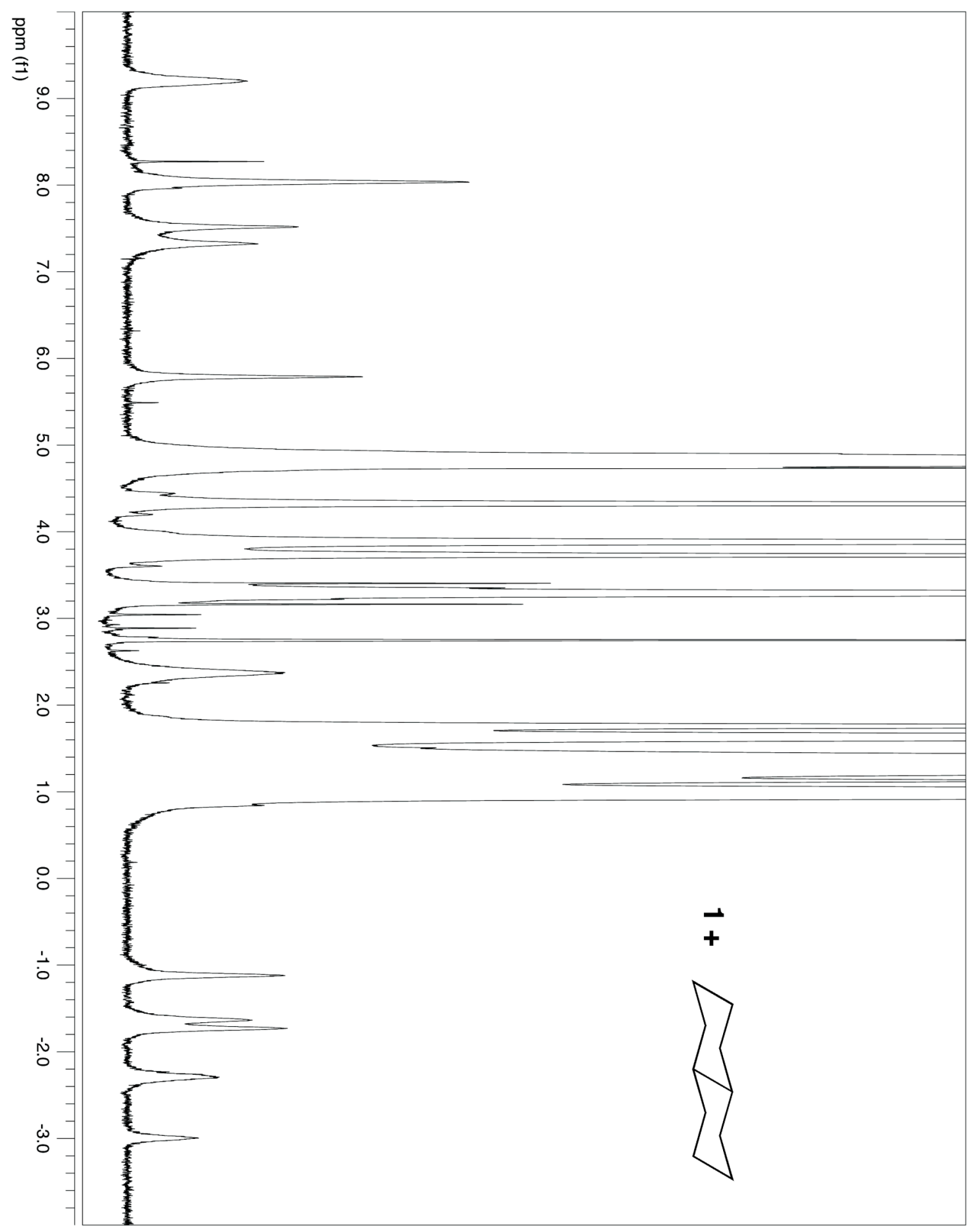

S-10 


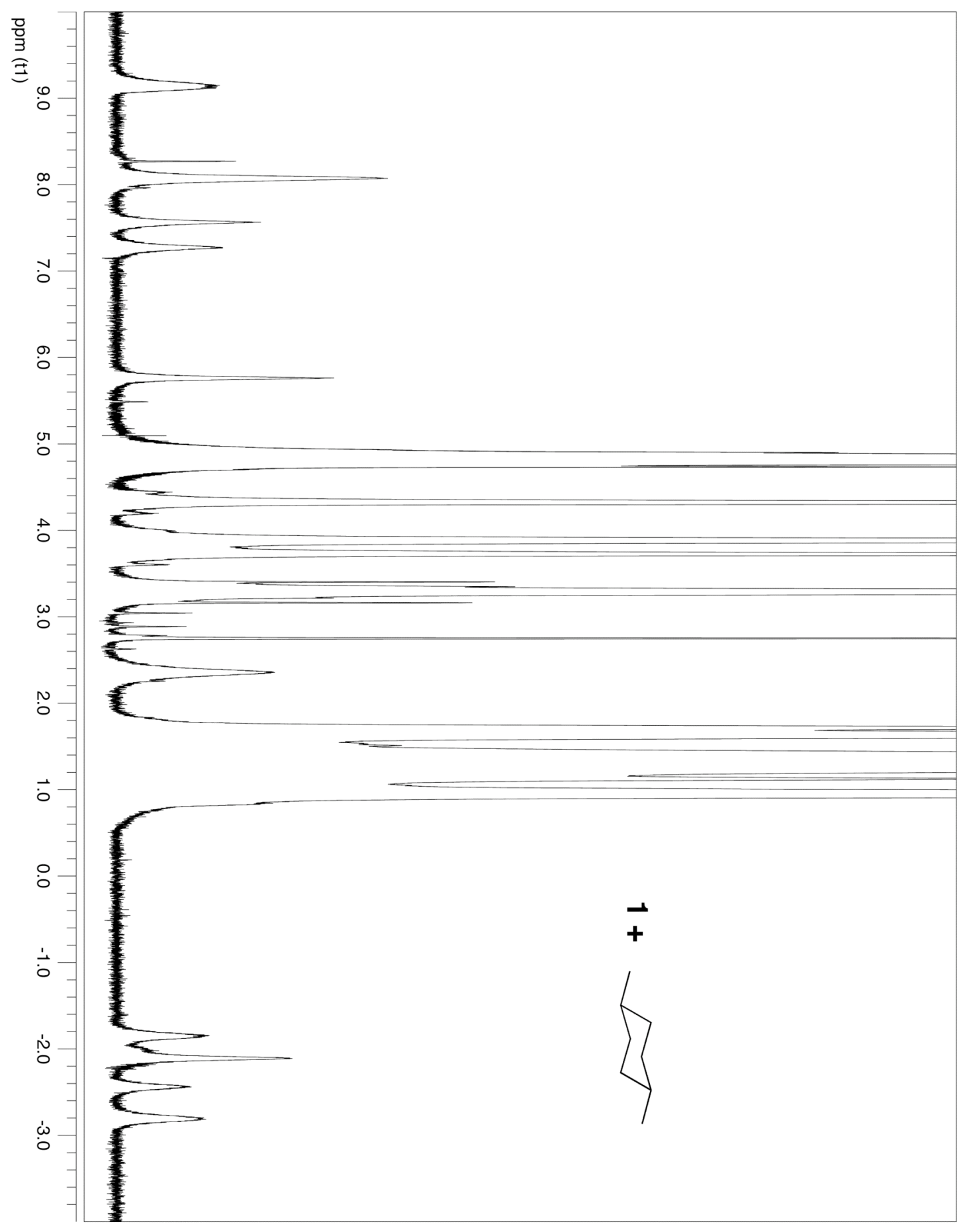

S-11 


\section{Spectra of Adamantylamine in Various Cavitands in PC Micelles}

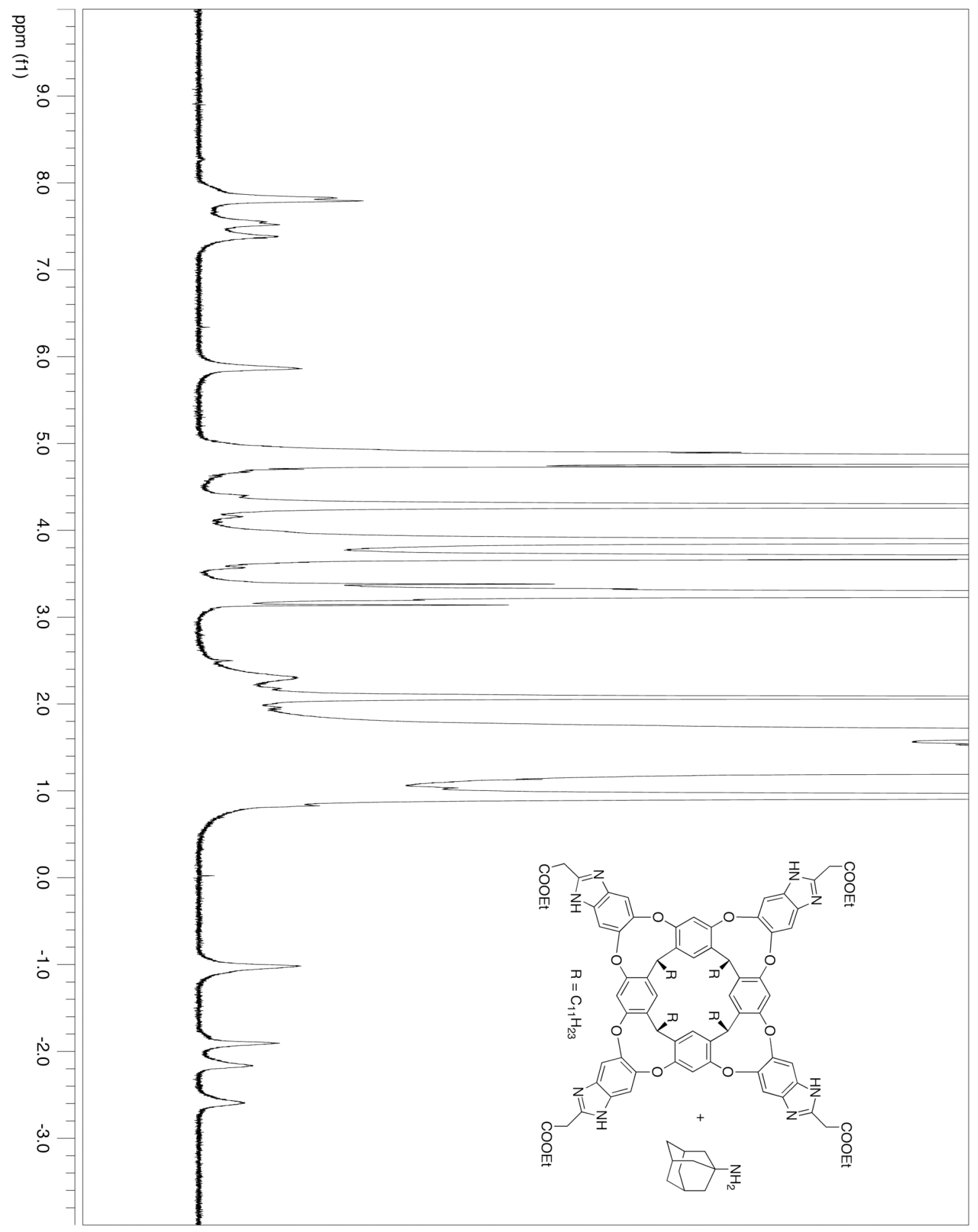




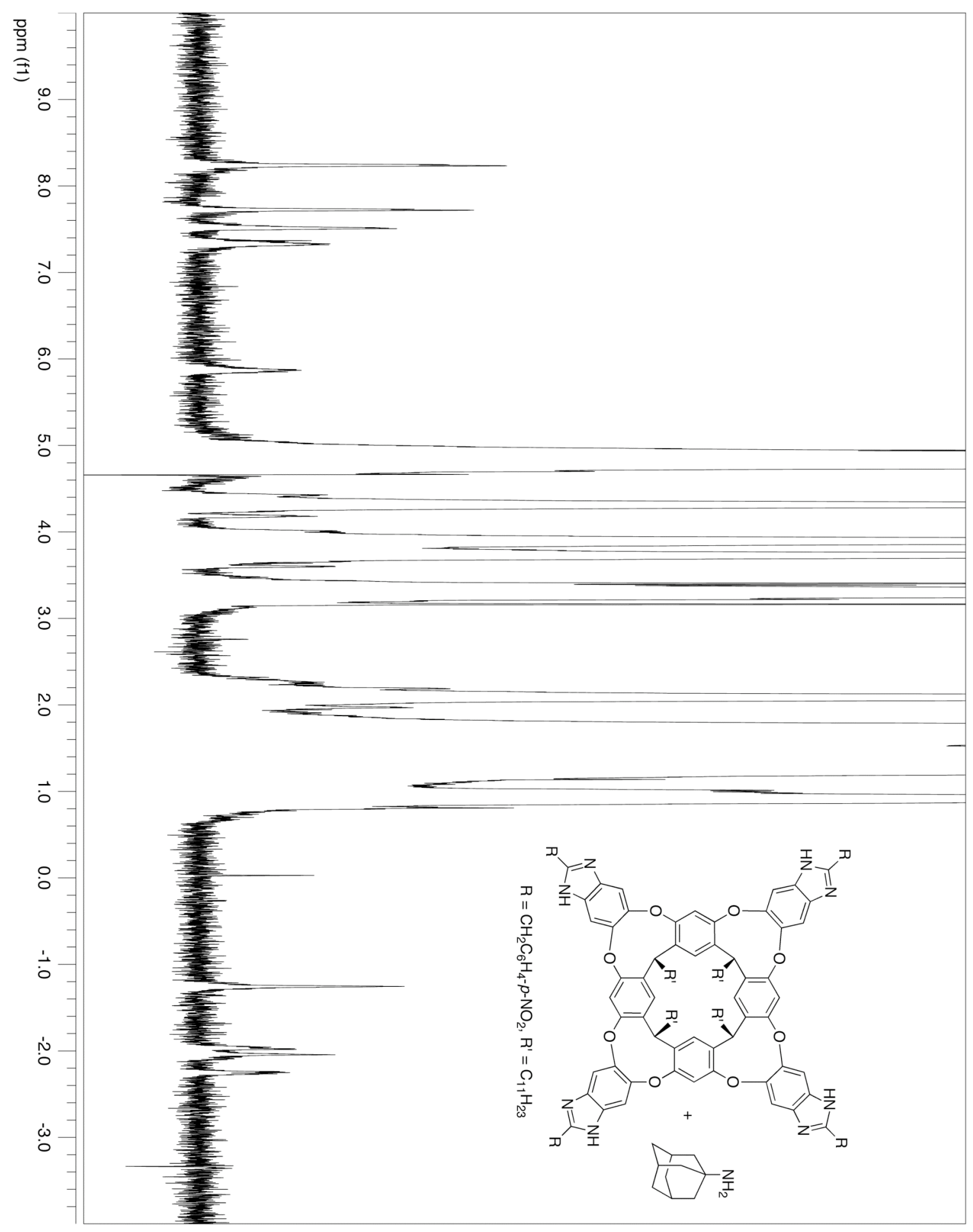

S-13 


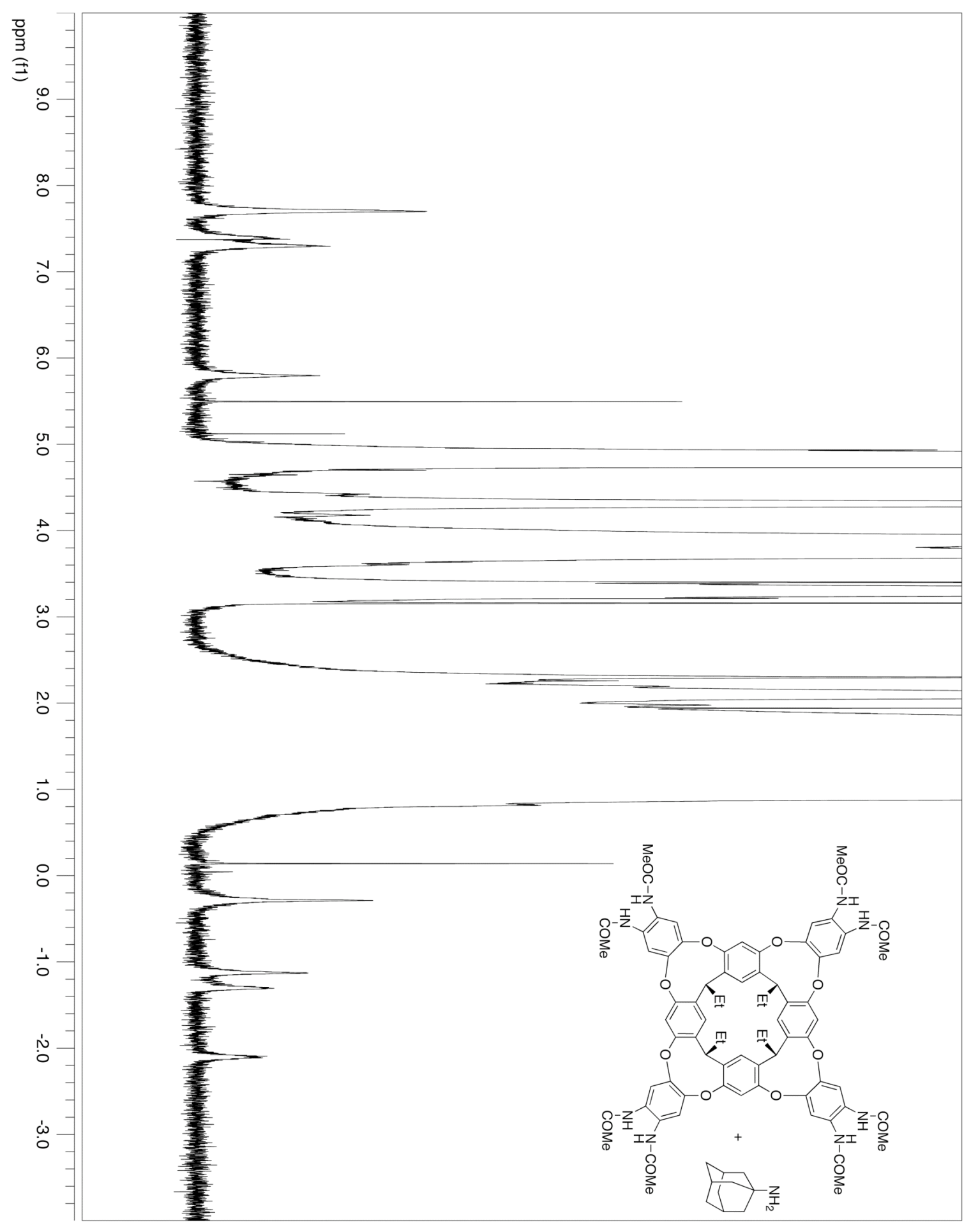




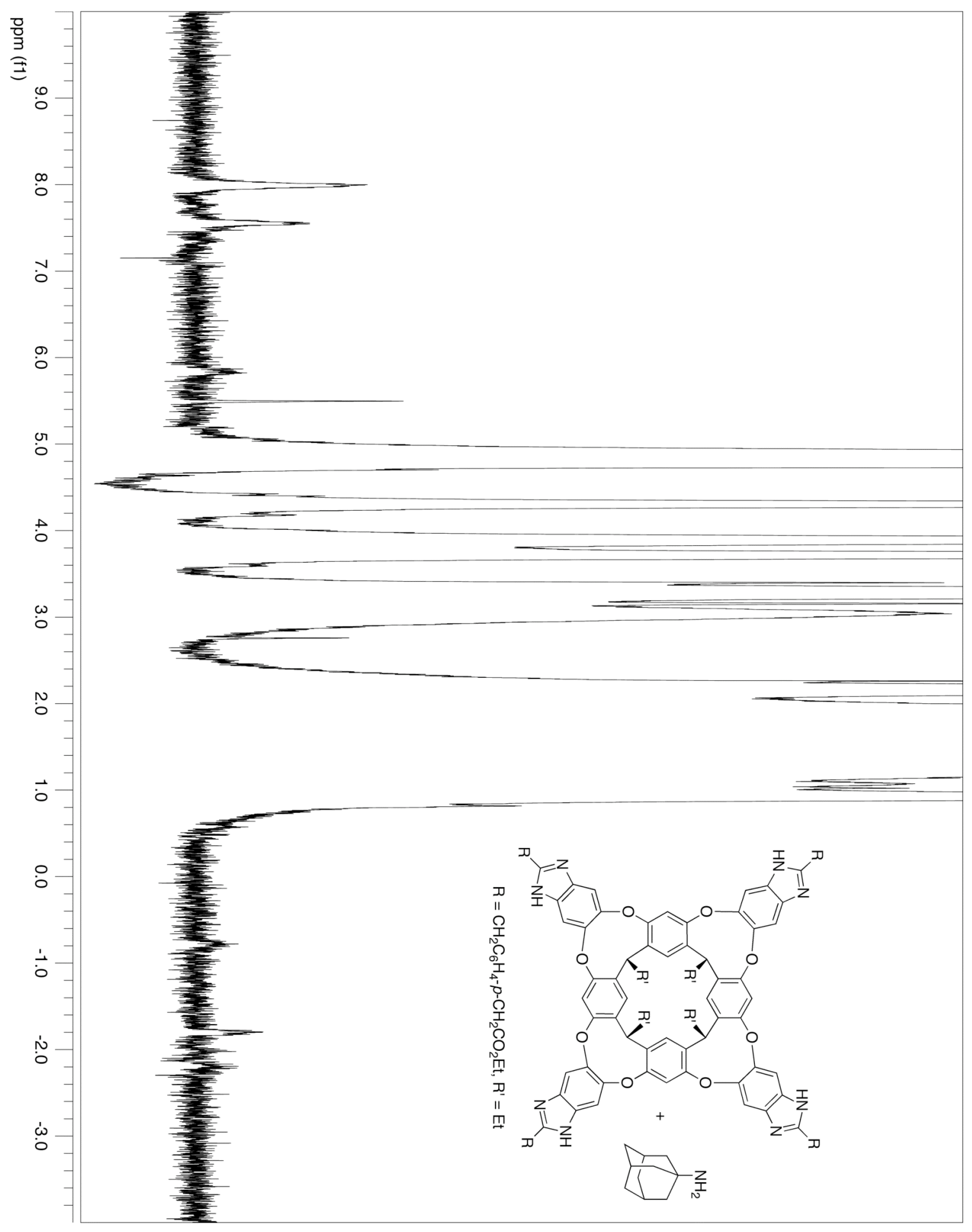

$S-15$ 


\section{Additional Spectroscopic Data}

$\mathrm{DCl}$ Titration of 1 in 2:1 THF $d_{8}: \mathrm{D}_{2} \mathrm{O}$
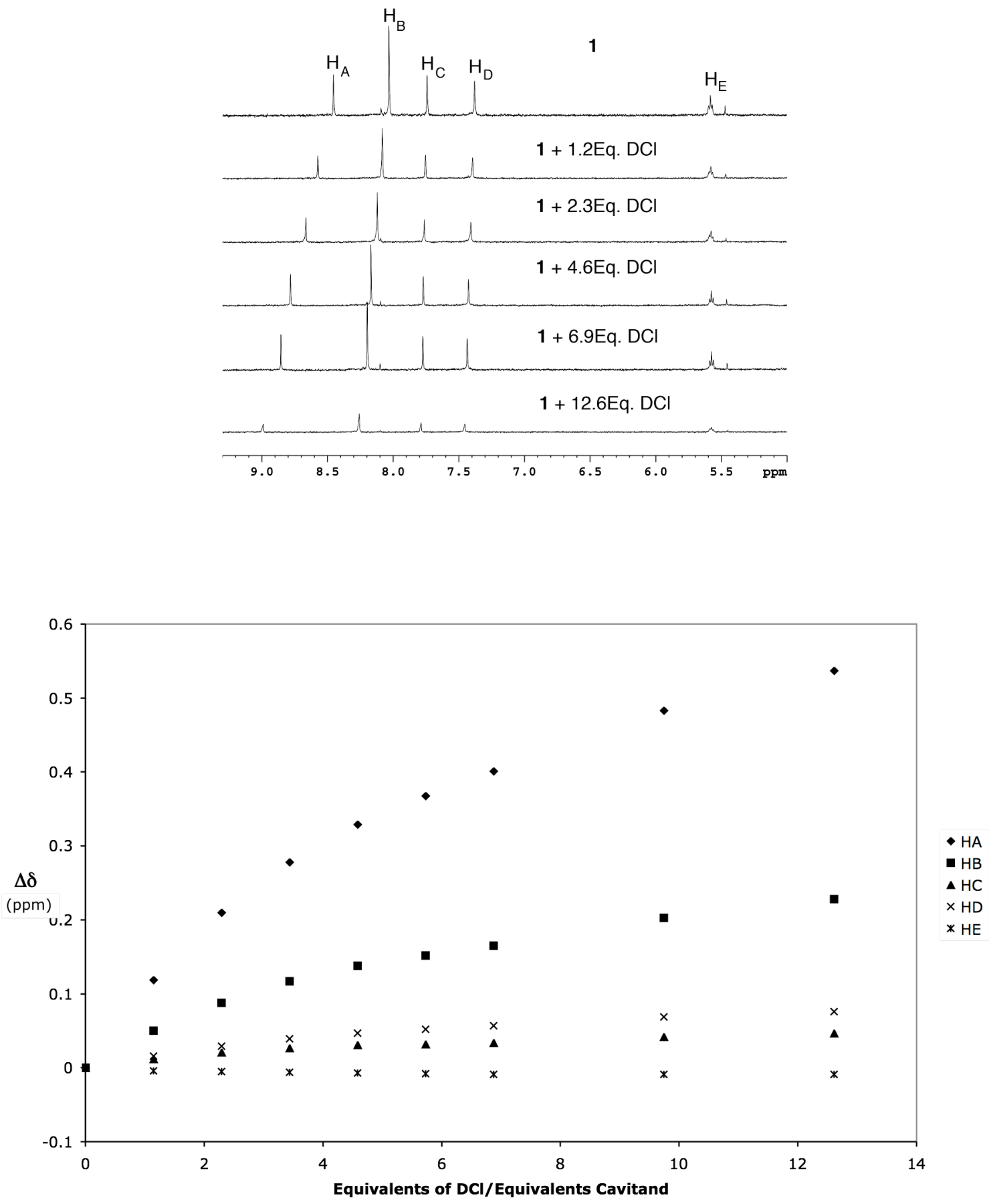
DOSY Spectrum for $\mathbf{1}$ with adamantylamine in DPC micelles. $\mathrm{D}_{2} \mathrm{O}$ and free adamantylamine have differing diffusion coefficients. The remainder of signals have 1 common diffusion coefficient - indicating that bound host and guest are a part of one larger DPC assembly. Measurements made using both peak height and area are shown. Values calculated using the built in analysis features of MestReC.
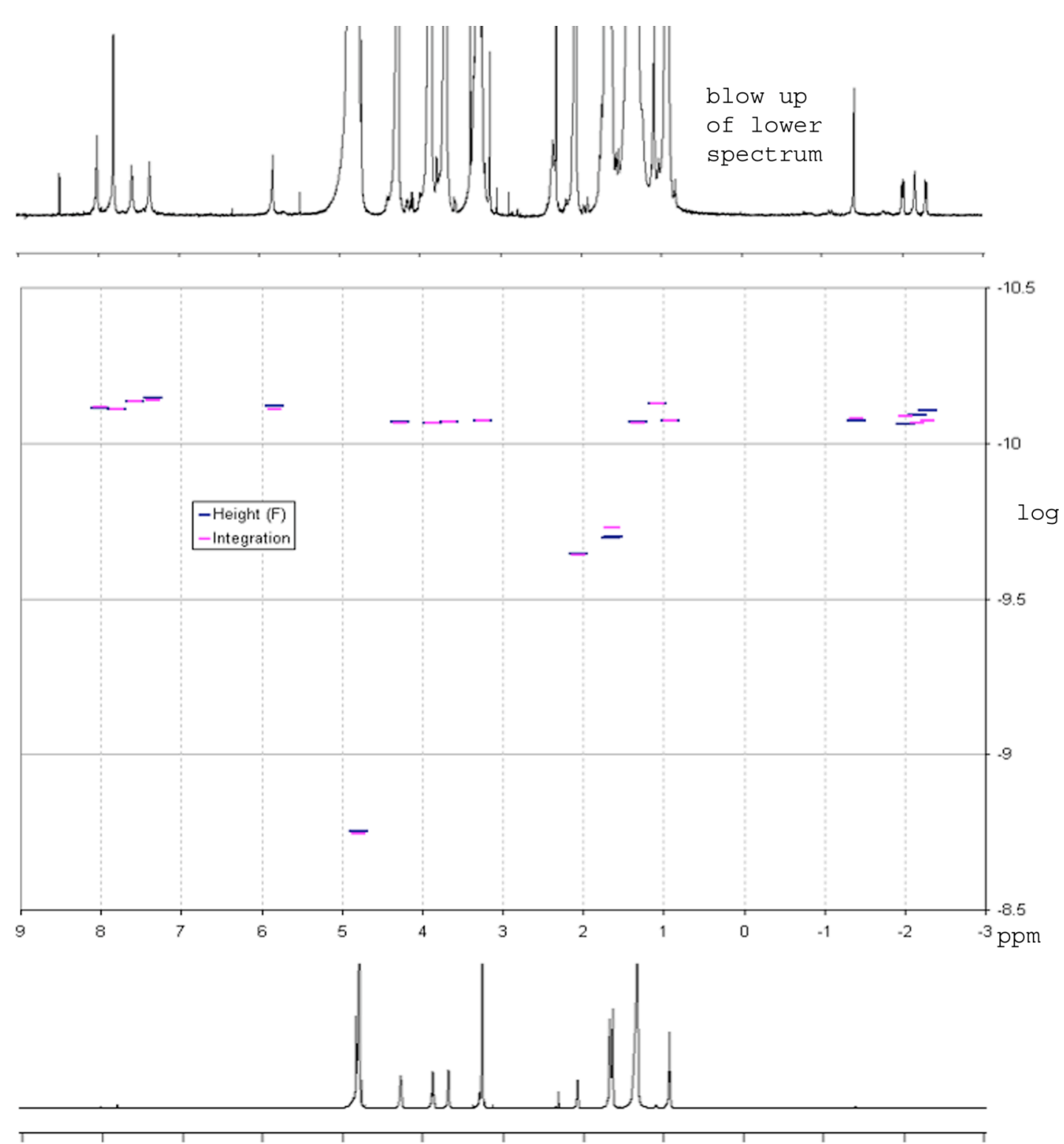